\title{
FRASA DIREKTIF YANG BERUNSUR DI, DARI, DAN UNTUK DALAM BAHASA INDONESIA: KAJIAN SINTAKTIS DAN SEMANTIS
}

\author{
Agus Nero Sofyan \\ Prodi Sastra Indonesia Fakultas Ilmu Budaya Universitas Padjadjaran \\ E-mail sofyanagusnero@gmail.com
}

\begin{abstract}
ABSTRAK. Penelitian ini berjudul "Frasa Direktif yang Berunsur Di, Dari, dan Untuk dalam Bahasa Indonesia: Kajian Sintaktis dan Semantis". Penelitian ini dilakukan dengan menggunakan metode kualitatif. Data yang digunakan diambil dari surat kabar yang ada pada situs internet dan data buatan (penulis). Teori yang digunakan adalah frasa, preposisi, jenis frasa, distribusi frasa, inti kategori frasa, makna gramatikal, dan peran semantis. Masalah yang dibahas adalah distribusi frasa direktif yang berunsur di, dari, dan untuk, kategori konstituen pascafrasa direktif yang berunsur di, dari, dan untuk, makna frasa direktif yang berunsur di, dari, dan untuk, serta peran semantis konstituen pascafrasa direktif yang berunsur di, dari, dan untuk. Dari hasil penelitian ditunjukkan bahwa unsur frasa direktif yang berunsur di, dari, dan untuk berdistribusi di depan, di tengah, dan di akhir suatu kalimat. Kategori konstituen pascafrasa direktif yang berunsur di, dari, dan untuk adalah nomina, ajektiva, frasa nominal, frasa verbal, dan frasa numeralia. Makna yang diemban frasa direktif yang berunsur di, dari, dan untuk adalah tempat berada yang permananen, waktu sedang berlangsung, tempat yang beruang/berdimensi, tempat asal, bahan, sebab/alasan, hasil/perolehan, waktu berjangka, peruntukan, dan kegunaan. Peran semantis konstituen pascafrasa direktif yang berunsur di, dari, dan untuk adalah pelaku, pengalam, penderita, tempat, perlawanan, penyebab, hasil, dan keadaan.
\end{abstract}

Kata kunci: frasa direktif, preposisi, distribusi, makna, peran

\section{DIRECTIVE PHRASE WHICH CONTAIN IN, OF, AND, FOR IN INDONESIAN: STUDY SYNTACTICALLY AND SEMANTICALLY}

\begin{abstract}
This research is entitled "The Directive Phrase with the Elemens In, From, and To in Indonesian Language: Syntactic and Semantic Study”. The method used in this study is a qualitative method. The data are taken from the newspapers that exist in the internet site and artificial data (made by the author). The theory are used phrase, preposition, type of phrase, distribution of the phrase, categories core of phrase, grammatical meaning, and semantic role. The issue that discussed is the distribution of the directive phrase that have the elemens in, from, and to, the constituent category of directive postphrase have elemens in, from, and to, meaning of the directive phrase with the elemens in, from, and to, also semantic role constituents in postphrase directive which has the elemens of in, from, and to. Based on the research, it is indicated that the directive phrase with the elements of in, from, and to had distribution in the front, in the middle, and in the end of the sentence. Constituents category of directive postphrase have the elemens of in, from, and to are the noun, adjective, noun phrase, verbal phrase, and numeral phrase. The meaning in directive phrase that have the elemens of in, from, and to are the meaning of the directive phrase that have the elemens in is a permanent place, happening time, dimensional place, origin, materials, causes, result, time future, for the sake of, and function. The semantic role of directive postphrase that have the elemens of in, from, and to are the agent, experincer, objecct, place, resistance, causes, results, and circumstances.
\end{abstract}

Key words: directive phrase, preposition, distribution, meaning, role

PENDAHULUAN

Berbicara tentang frasa dalam bahasa Indonesia memang sangat menarik dan bervariatif sebab dapat dikaji dari berbagai sudut. Frasa merupakan satuan sintaksis di samping klausa dan kalimat. Frasa dapat terbentuk dari dua kata atau lebih. Keberadaan frasa dapat berdiri sendiri, yaitu tidak bergantung pada satuan bahasa lain. Akan tetapi, suatu frasa dapat pula berada dalam kalimat, yaitu mengisi fungsi sintaktis tertentu, misalnya, mengisi fungsi subjek, predikat, objek, pelengkap, atau keterangan. Hal itu dapat dilihat pada ekspresi berikut.

(1) Kedua peneliti muda itu sedang mengkaji bahasabahasa nusantara.

Kalimat tersebut memiliki fungsi sintaktis SPO yang dibentuk oleh tiga frasa, yaitu frasa yang mengisi fungsi subjek (kedua peneliti muda itu), frasa yang mengisi fungsi predikat (sedang meneliti), dan frasa yang mengisi fungsi objek (bahasa-bahasa nusantara).

Frasa dapat diartikan satuan gramatik atau satuan bahasa yang berwujud dua kata atau lebih yang tidak melebihi batas fungsi unsur klausa (Ramlan, 2001:138). Struktur suatu frasa ada yang renggang, misalnya, mobil baru (mobil yang baru) dan ada pula yang rapat, misalnya, di Bandung. Agar keberadaan frasa lebih jelas dan mudah dipahami, berikut ini adalah klasifikasi frasa secara distributif dan secara inti kategorial.

Frasa dapat diklasifikasikan beradasrkan inti kategorinya, yaitu frasa verbal, frasa nominal, frasa ajektival, frasa pronominal, frasa adverbial, frasa numeralia, dan frasa preposisional (Kridalaksana, 1994:125 dan Ramlan, 2001:141). Secara berturut-turut contoh frasa (-frasa) itu dapat dilihat pada bagian kalimat yang dicetak miring sebagai berikut. 
(2) Kami akan menyimpulkan hasil penelitian itu.

(3) Mahasiswa baru Unpad ber-KKN di Sumedang, Jawa Barat.

(4) Mereka sangat rajin belajar.

(5) Anda sekalian harus berjuang untuk kemajuan bangsa dan negara.

(6) Pertandingan itu akan digelar malam hari di Gelora Bung Karno.

(7) Petani itu memiliki tiga ekor sapi.

(8) Kami berkuliah di Kota Bandung.Pengklasifikasian frasa yang kedua berdasarkan distribusi, yaitu frasa endosentris (atributif, koordinatif, dan apositif) dan frasa eksosentris (direktif dan objektif); hal ini sejalan dengan Kridalaksana (1994:125), Ramlan (2001:141), dan Djajasudarma (2003:11).

(9) Kereta malam itu datang terlambat.

(10) Tua dan muda juga pria atau wanita berkedudukan sama dalam hukum.

(11) Presiden, kepala negara, di Indonesia dipilih oleh rakyat.

(12) Dari Medan kami akan melanjutkan perjalanan ke Kota Makasar.

(13) Mencintai anak yatim merupakan perbuatan yang mulia.

Pada kalimat (9) sampai dengan (13) tersebut, tampak bagian kalimat yang berscetak miring itu adalah frasa atributif (kereta malam), frasa koordinatif (tua dan muda pria atau wanita), frasa apositif (presiden kepala negara), frasa direktif (dari Medan ke Kota Makasar), dan frasa objektif (mencintai anak Yatim).

Dalam penelitian ini, akan dikajifrasa eksosentris, khususnya frasa direktif. Frasa direktif memiliki direktor. Unsur yang bergabung dengan direktor mempunyai kaitan yang erat sebagai satu kesatuan (Djajasudarma, 2003:17). Selanjutnya, Kridalaksana (1994:128) mengatakan bahwa frasa direktif dapat pula disebut frasa preposisional agar kategori katanya dapat ditentukan, misalnya, dari Jakarta, oleh rakyat, untuk mereka.

Penulis berpendapat bahwa frasa direktif dapat diartikan frasa yang terbentuk dari paduan preposisi dengan unsur lain, yaitu nomina, frasa nominal, dan pronomina, misalnya, ke Sumatra, di rumah besar, pada kami.

Pada hakikatnya unsur pembentuk frasa direktif adalah preposisi dan nomina. Preposisi adalah kategori yang berada di depan kategori lain, yaitu terutama kategori nomina sehingga membentuk frasa eksosentris direktif (Kridalaksana, 1994:95).

Yang tergolong pada kategori preposisi, antara lain, adalah di, ke, dari, pada, dalam, dengan, oleh, kepada, untuk, bagi, atas, tentang. Nomina adalah kategori yang secara sintaktis memiliki kemampuan untuk divalensikan dengan partikel bukan, dari, dan tidak dapat divalensikan dengan partikel tidak (Chaer, 1990:24 dan Kridalaksana, 1994:68). Contoh kategori nomina, misalnya, rumah, batu, gunung, laut, pantai, kertas, radio, mobil.

Dalam penelitian ini, frasa direktif dikaji secara sintaktis dan semantis. Kajian sintaktis meliputi distribusi frasa direktif dan kategori konstituen pascafrasa direktif, sedangkan kajian semantis adalah makna yang diemban frasa direktif dan peran semantis konstituen pascafrasa direktif. Berbicara tentang distribusi berkaitan dengan posisi frasa direktifdalam konteks kalimat; kategori dapat berupa, misalnya, nomina, verba, ajektiva, pronomina, adverbia, numeralia, preposisi, dan konjungsi. Makna yang diemban berkaitan dengan makna gramatikal. Dikatakan oleh Djajasudarma (2009:16) bahwa makna gramatikal adalah makna kata yang menyangkut hubungan intrabahasa atau makna yang muncul sebagai akibat berfungsinya sebuah kata, farasa, klausa dalam kalimat atau satuan yang lebih besar. Selanjutnya, peran semantis dapat berupa pelaku, penderita, pengalam, penerima, atribut, penyerta, tempat, sumber, waktu, alat, asal, tujuan, cara, pembanding, keadaan, akibat, syarat (Alwi, dkk.: 2003:334, Ramlan, 2001:93, dan Verhaar, 2004:199).

Frasa direktif yang kaji dalam penelitian ini adalah frasa direktif yang berunsur $d i$, dari, dan untuk. Alasan frasa direktif yang berunsur di, dari dan untuk dikaji karena memiliki kevariatifan baik itu dari segi distribusi, kategori, makna, maupun peran semantis.

\section{METODE}

Dalam penelitian ini digunakan metode kualitatif. Penerapan metode kualitatif ini sejalan dengan pernyataan Djajasudarma (2006:10) yang mengungkapkan bahwa metode kualitatif merupakan proseduryang menghasilkan data secara deskriptif baik itu tulis maupun lisan yang berkembang atau berada di masyarakat. Dalam metode ini, data dihasilkan secara deskriptif maksudnya adalah untuk membuat gambaran, lukisan secara sistematis, faktual, dan akurat mengenai data, sifat, serta kaitannya dengan fenomena-fenomena.

Metode kajian yang digunakan adalah metode kajian distribusional. Hal ini sejalan pula dengan yang dinyatakan Djajasudarma (2006:69) bahwa dalam metode ini digunakan alat penentu unsur bahasa itu sendiri karena setiap unsur bahasa berkaitan satu dengan yang lain untuk membentuk satu kesatuan yang padu. Metode ini diterapkan, misalnya, untuk mengidentifikasi kategori preposisi dan nomina sebagai unsur utama frasa direktif.

Metode pengumpulan data yang digunakan adalah metode simak. Hal ini sejalan dengan pendapat Sudaryanto (1993:133) bahwa dalam metode simak digunakan teknik dasar yang meliputi teknik sadap, libat cakap, simak bebas libat cakap, rekam, dan catat. Teknik cacat digunakan dalam penelitian ini, yaitu dengan langkah-langkah sebagai berikut:

1. membaca dan menandai setiap kalimat yang berisikan frasa direktif;

2. mencatat setiap kalimat yang berisikan frasa direktif yang berunsur di, dari, dan untuk;

3. menyeleksi frasa direktif yang berunsur di, dari, dan untuk;

4. mengklasifikasikan frasa direktif yang berunsur $d i$, dari, dan untuk; 
5. mengartukan korpus frasa direktif yang berunsur di, dari, dan untuk.

\section{HASIL DAN PEMBAHASAN}

\section{Distribusi Frasa Direktif yang Berunsur Di, Dari, dan Untuk}

Berikut ini adalah data (-data) yang menunjukkan distribusi frasa direktif yang berunsur di, dari, dan untuk.

(1) Di pasar daerah Kebayoran Lama, PKL kembali memenuhi trotoar dan badan jalan. (Kompas, 05/03/2014)http://megapolitan.kompas.com/ read/2014/03/05/0820428/Pemprov.Tak.Konsisten. Pejalan.Kaki.Terpaksa.Berjalan.di.Badan.Jalan.

(2) Di putaran pertama, pemilih yang tidak menggunakan haknya sejumlah 36,38\%.(Kompas,05/03/2014) http://politik.kompasiana.com/2014/03/05/angkagolput-akan-turun-karena- jokowi-639442.html.

(3) Dari data Pemilu 2009, memang terlihat adanya peningkatan partisipasi pemilih dari pemilu sebelumnya. (Kompas, 05/03/2014) http://politik. kompasiana.com/2014/03/05/angka-golput-akanturun-karena-jokowi-639442.html. Dari total out standing pinjaman tersebut, 91,8 persen disalurkan ke berita sektor perdagangan, restoran dan hotel. (Republika, 04/03/2014) http://www.republika.co.id// ekonomi/bisnis/14/03/04/n1wmyr-pnm-bukukanpertumbuhan-laba-116-persen. Untuk kebijakan kenaikan harga BBM, pemerintah akan menyesuaikan anggaran pendapatan dan belanja negara (APBN). (Kompas,22/03/2014)http://bisniskeuangan.kompas. com/read/2014/03/22/1549466/Kenaikan. Harga. BBM. Lebih. Efekt Untuk kelancaran perjalanan ini, para wisatawan harus menaati aturan dari biro perjalanan. (DB)

Pada data (1) sampai dengan (6), tampak bahwa frasa direktif yang berunsur di, dari dan untuk, yaitu di pasar daerah Kebayoran Lama, di putaran pertama, dari data Pemilu 2009, dari total outstanding pinjaman tersebut, untuk kebijakan kenaikan harga BBM, dan untuk kelancaran perjalanan ini dalam kalimat tersebut berdistribusi pada awal kalimat. Selain dapat berdistribusi pada awal kalimat, frasa direktif yang berunsur di, dari dan untuk tersebut dapat pula berdistribusi di tengah kalimat.

(1) PKL, di pasar daerah Kebayoran Lama, kembali memenuhi trotoar dan badan jalan.

(2) Pemilih yang tidak menggunakan haknya, di Putaran pertama, sejumlah $36,38 \%$.

(3) Memang terlihat, dari data Pemilu 2009, adanya peningkatan partisipasi pemilih dari pemilu sebelumnya.

(4) (Sejumlah) 91,8 persen, dari total outstanding pinjaman tersebut, disalurkan ke sektor perdagangan, restoran dan hotel.

(5) Pemerintah, untuk kebijakan kenaikan harga BBM, menyesuaikan anggaran pendapatan dan belanja negara (APBN).
(6) Para wisatawan, untuk kelancaran perjalanan ini, menaati aturan dari biro perjalanan.

Selanjutnya, selain dapat berdistribusi di awal dan di tengah kalimat, frasa direktif yang berunsur di, dari, dan untuk dapat pula berdistribusi di akkhir kalimat.

(1) PKL kembali memenuhi trotoar dan badan jalan di pasar daerah Kebayoran Lama.

(2) Pemilih yang tidak menggunakan haknya sejumlah $36,38 \%$ di putaran pertama.

(3) Memang terlihat adanya peningkatan partisipasi pemilih dari pemilu sebelumnya dari data Pemilu 2009.

(4) (Sejumlah) 91,8 persen ke sektor perdagangan, restoran dan hotel dari total outstanding pinjaman tersebut.

(5) Pemerintah menyesuaikan anggaran pendapatan dan belanja negara (APBN) untuk kebijakan kenaikan harga BBM.

(6) Para wisatawan harus menaati aturan dari biro perjalanan untuk kelancaran perjalanan ini.

Tabel 1. Distribusi Frasa Direktif yang Berunsur Di, Dari, dan Untuk

\begin{tabular}{ccccc}
\hline No. & $\begin{array}{c}\text { Frasa } \\
\text { Direktif } \\
\text { Berunsur }\end{array}$ & \multicolumn{2}{c}{ Distribusi dalam Kalimat di } \\
Awal & Tengah & Akhir \\
\hline 1 & di & $\sqrt{ }$ & $\sqrt{ }$ & $\sqrt{ }$ \\
2 & dari & $\sqrt{ }$ & $\sqrt{ }$ & $\sqrt{ }$ \\
3 & untuk & $\sqrt{ }$ & $\sqrt{ }$ & $\sqrt{ }$ \\
\hline
\end{tabular}

Kategori Konstituen Pascafrasa Direktif yang Berunsur Di, Dari, dan Untuk

Berikut ini adalah data-data yang menunjukkan kategori konstituen pascafrasa direktif yang berunsur di, dari, dan untuk.

(7) Diputaran pertama, pemilih yang tidak menggunakan haknya sejumlah 36,38\%. (Kompas,05/03/2014) http://politik.kompasiana.com/2014/03/05/angkagolput-akan-turun-karena-jokowi-639442.html.

(8) Di pemilihan pilkada semakin ketat persaingan calon dari berbagai partai. (DB)

(9) Dari survei yang sudah dipublikasikan, elektabilitas Gerindra belum mendekati 20 persen. (Kompas, 05/03/2014)http://indonesiasatu.kompas.com/ $\mathrm{read} / 2014 / 03 / 05 / 1406156 /$ gerindra.dinilai.sulit. usung.prabowo-ahok.di.pilpres.

(10) Sampai sekarang, laporan dari bagian kesehatan tidak ada yang meninggal. (Kompas, 05/03/2014). http://megapolitan.kompas.com.read/2014/ 03/05/1246374/TNI.Turunkan.Tim.Investigasi. Usut.Ledakan.Gudang.TNI.AL.

(11) Untuk berkembang ke depannya, ia berpikir akan sangat sulit meskipun terus dicoba. (Kompas,17/03/2014) http://brasil2014.kompas. com/read/2014/03/17/2012467/.Tak.Ada.yang. Tahu. Limit.Kemampuan.Messi.

(12) Untuk meningkatkan keamanan di kompleks itu, sepuluh orang satpam harus berjaga setiap malam hari. (DB) 
Pada kalimat (7) sampai dengan (12), tampak bahwa kategori konstituen pascafrasa direktif yang berunsur di, dari, dan untuk secara berturut-turut adalah frasa nominal dan frasa ajektival (pemilih yang tidak menggunakan haknya dan semakin ketat), frasa nominal dan frasa verbal (elektabilitas Gerindra dan tidak ada), serta pronomina dan frasa numeralia (ia dan sepuluh orang satpam).

Tabel 2. Kategori Konstituen Pascafrasa Direktif yang Berunsur Di, Dari, dan Untuk Makna Frasa Direktif yang Berunsur Di, Dari, dan Untuk

\begin{tabular}{ccccccc}
\hline No. & $\begin{array}{c}\text { Frasa } \\
\text { Direktif } \\
\text { Berunsur }\end{array}$ & $\begin{array}{c}\text { Frasa } \\
\text { Nominal }\end{array}$ & $\begin{array}{c}\text { Frasa } \\
\text { Verbal }\end{array}$ & $\begin{array}{c}\text { Frasa } \\
\text { Ajektival }\end{array}$ & Pronomina & $\begin{array}{c}\text { Frasa } \\
\text { Numeralia }\end{array}$ \\
\hline 1 & Di & $\sqrt{ }$ & & $\sqrt{ }$ & \\
2 & Dari & $\sqrt{ }$ & $\sqrt{ }$ & & & \\
3 & Untuk & & & & $\sqrt{ }$ & $\sqrt{ }$ \\
\hline
\end{tabular}

Berikut ini adalah data (-data) yang menunjukkan makna frasa direktif yang berunsur di, dari, dan untuk.

(13) Infrastruktur perdagangan akan dikhususkan bagi pedagang pasar dan PKL yang kini belum tertampung di lokasi binaan.(Kompas,05/03/2014) http://megapolitan.kompas.com/read/2014/03 /05/0820428/Pemprov.Tak.Konsisten.Pejalan.Kaki. Terpaksa.Berjalan.di.Badan.Jalan.

(14) Di Indonesia, jumlah penganggur berusia 19-29 tahun mencapai 4,9 juta orang dari total 7,4 juta penganggur. (Kompas,04/03/2014)http://bisniskeuangan.kompas. com/read/2014/03/04/0916541/Jumlah.Penganggur. Muda.Naik.

(15) Di pemilu tahun 2009, dukungan untuk PDI kembali turun hingga tinggal 14,03\%. (Kompas, 05/03/2014) http://politik.kompasiana.com/2014/03/05/angkagolput-akan-turun-karena- jokowi-639442.html.

(16) Di putaran pertama, pemilih yang tidak menggunakan haknya sejumlah 36,38\%. (Kompas,05/03/2014) http:// politik.kompasiana.com/2014/03/05/angka-golputakan-turun-karena- jokowi-639442.html.

(17) Novel Layar Terkembang disimpan adik di lemari buku. (DB)

(18) Kopi tumbuk yang dituangkan di gelas itu mengundang selera kakek. (DB)

(19) Perwakilan ACV-CSC dari Belgia mengatakan bahwa mereka aktif berkolaborasi dalam jaringan internasional dengan serikat buruh. (Kompas, 04/03/2014)http://bisniskeuangan.kompas.com/ read/2014/03/04/0916541/Jumlah.Penganggur. Muda.Naik.

(20) Bersama Mark Zuckerberg, Moskovitz mendirikan Facebook hingga dikeluarkan dari Harvard University. (Kompas, 04/03/2014) http://bisnis keuangan.kompas.com/read/2014/03/04/1856437/ Belum. Genap. 30. Tahun. 5.Anak.Muda.Ini.Masuk. Daftar.Orang.Terkaya.

(21) Pakaian pejabat yang merakyat itu terbuat dari katun. (DB)

(22) Genting rumah kami berasal dari tanah liat. (DB)

(23) Dari perbuatannya itu, mereka harus berurusan dengan polisi. (DB)

(24) Dari ketidakjujurannya, dia diberhentikan secara tidak hormat dari pekerjaannya. (DB)(25) Dari laporan keuangan perseroan, PNM mencatat pinjaman yang telah direstrukturisasi sebesar Rp 324,03 miliar. (Republika,04/03/2014) http://www.republika.co.id/ berita/ekonomi/bisnis/14/03/04/n1wmyr-pnmbukukan-pertumbuhan-laba-116-persen.

(26) Barcelona akan menjamu Madrid sebagai penguasa klasemen Liga BBVA dengan 8 poin dari enam pertandingan.(Kompas,02/10/2012)http://bola. kompas.com/read/2012/10/02/07044286/Messi. Kalahkan.Madrid.Adalah.Hal.Terindah.

(27) Dari pukul 08.00 s.d. 16.00, PNS bekerja selama lima hari. (DB)

(28) Dari pagi pagi hingga malam, Amir bekerja untuk menghidupi keluarga. (DB)

(29) Untuk tampil di Piala Dunia 2014, Totti harus terus memperlihatkan penampilan yang impresif. (Kompas, 20/03/2014) http://brasil2014.kompas.com/ $\mathrm{read} / 2014 / 03 / 20 / 2301314 /$ Totti.Buka.Pintu.untuk. Timnas.Italia

(30) Wiranto menilai putusan tersebut secara tidak langsung merampas hak politik masyarakat dalam mencari pemimpin berkualitas untuk bangsa. (Kompas,21/03/2014) http://nasional.kompas.com/ read/2014/03/21/2047430/Gugatan.UU.Pilpres. Ditolak Wiranto.Sebut.MK. Pasung. Hak.Rakyat

(31) Seharusnya, beri kesempatan Anas untuk merinci. (Kompas,21/03/2014)http://nasional.kompas.com/ read/2014/03/21/2102048/Pengacara.Anas.Uang. Muka.Harrier.dari.SBY

(32) Menurut Ical, video sengaja disebarkan pada saat kampanye menjelang pemilu untuk menjatuhkannya. Kompas,23/03/2014)http://nasional.kompas.com/

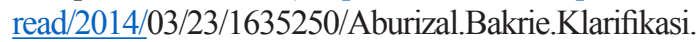

Makna frasa direktif berunsur di yang tampak pada kalimat (13) sampai dengan (18) adalah tempat berada yang permananen (di lokasi binaan dan di Indonesia), waktu sedang berlangsung (di pemilu tahun 2009 dan di putaran pertama), dan tempat yang beruang/ berdimensi (di lemari dan di gelas itu).

Pada kalimat (19) sampai dengan (28), makna yang diemban frasa direktif yang berunsur dari adalah tempat asal (dari Belgia dan Harvard University), bahan (dari katun dan dari tanah liat), sebab (dari perbuatannya dan dari ketidakjujurannya), hasil/perolehan (dari laporan keuangan perseroan dan dari enam pertandingan), serta waktu berjangka (dari pukul 08.00 s.d. 16.00 dan dari pagi hingga malam).

Makna frasa direktif yang berunsur untuk adalah peruntukan/alih-alih bagi (untuk bangsa) serta kegunaan (untuk tampil, untuk merinci, dan untuk menjatuhkannya) yang terlihat pada kalimat (29) sampai dengan (32).

\section{Peran Semantis Frasa Direktif yang Berunsur Di, Dari, dan Untuk}

Berikut ini adalah data (-data) yang menunjukkan peran semantis konstituen pascafrasa direktif yang berunsur di, dari dan untuk.

(33) Di dalam negeri sentimen positif juga tersedia. 
(Kompas,05/03/2014)http://bisniskeuangan. kompas.com/read/2014/03/05/0811364/Proyeksi. Rupiah.Masih.Rawan.Terkoreksi.

(34) Kini di Liga Indonesia para pesepak bola terkena imbas pembekuan PSSI oleh Menpora. (DB)

(35) Citibank Indonesia menargetkan pertumbuhan kartu kredit dan kartu debetnya di tahun ini mencapai 20 persen.(Kompas,04/03/2014)http://bisniskeuangan. kompas.com/read/2014/03/04/2127452/Citibank. Targetkan.Pertumbuhan.Kartu.20.Persen.

(36) Di pemilu tahun 2014,PDIP (Partai Demokrasi Indonesia Perjuangan) dan para relawan bekerja keras agar meraih kemenangan. (DB)

(37) Dari hasil olah TKP, polisi menyimpulkan bahwa A dan $M$ terlibat dalam rencana pembunuhan Angeline. (DB)

(38) Sebagian kecil investasi Seri C Path berasal dari Bakrie, sedangkan sebagian besar lainnya berasal dari investor lain.(Kompas, 28/02/2014)http://tekno. kompas.com/read/2014/02/28/0727434/Sebenarnya. Berapa.Persen.Saham.Bakrie.di.Path.

(39) Dari peristiwa itu, mereka difitnah sehingga harus mendekam di jeruji besi selama 6 tahun. (DB)

(40) Dari hasil penelitian, debu merupakan penyebab utama pilek dan asma. (DB)

(41) Untuk negara-negara Eropa, Indonesia menjadi negara pengekspor timah. (DB)

(42) Untuk kebijakan kenaikan harga BBM, pemerintah menyesuaikan anggaran pendapatan dan belanja negara (APBN). (Kompas, 22/03/2014)http://bisniskeuangan. kompas.com/read/2014/03/22/1549466/Kenaikan. Harga.BBM.Lebih.Efektif

(43) Untuk pupuk sampah-sampah itu diproses menjadi kompos. (DB)

(44) Untuk beliau rumah mewah itu sudah kami persiapkan jauh-jauh hari. (DB)

Peran semantis yang diemban konstituen pasca -frasa direktif yang berunsur di yang tampak pada kalimat (33) sampai dengan (36) adalah keadaan (sentimen positif), pengalam (para pesepak bola), hasil (mencapai 20 persen), dan pelaku (PDIP Partai Demokrasi Indonesia Perjuangan) dan para relawan).

Selanjutnya, peran semantis konstituen pascafrasa direktif yang berunsur dari tampak pada kalimat (37) sampai dengan (40) adalah pelaku (polisi), pertentangan (sedangkan sebagian besar lainnya berasal dari investor lain), penderita (mereka), dan penyebab (debu).

Peran semantis yang ketiga adalah konstituen pascafrasa direktif yang berunsur untuk. Hal itu tampak pada kalimat (41) sampai dengan (44), yaitu pengalam (Indonesia), pelaku (pemerintah), sasaran (sampahsampah itu), dan tempat (rumah mewah itu).

\section{SIMPULAN}

Dari uraian tentang frasa direktif yang berunsur di, dari, dan untuk dapat disimpulkan hal-hal sebagai berikut.

(a) Frasa direktif adalah kelompok kata yang terbentuk dari paduan kategori preposisi dengan kategori lain, yaitu nomina, frasa nominal, dan pronomina, misalnya, di Indonesia, dari laporan keuangan perseroan,dan untuk beliau.

(b) Frasa direktif merupakan bagian dari frasa eksosentris, yaitu klasifikasi frasa yang didasarkan pada distribusi atau penyebaran dalam kalimat atau konstruksi tertentu.

(c) Secara distribusional, dalam konteks kalimat, frasa direktif yang berunsur di, dari, dan untuk berada pada posisi depan, tengah, dan akhir.

(d) Kategori konstituen pascafrasa direktif yang berunsur di, dari, dan untuk adalah frasa nominal, frasa ajektival, frasa verbal, pronomina, dan frasa numeralia.

(e) Makna gramatikal yang diemban frasa direktif yang berunsur di, dari, dan untuk ialah sebagai berikut. Makna frasa direktif yang berunsur di adalah tempat berada yang permanen, waktu sedang berlangsung, dan tempat yang beruang atau berdimensi. Makna frasa direktif yang berunsur dari adalah tempat asal, bahan, sebab, hasil/perolehan, dan waktu. Makna frasa direktif yang berunsur untuk adalah peruntukan (alih-alih bagi) dan kegunaan.

(f) Peran semantis yang diemban konstituen pascafrasa direktif yang berunsur di, dari, dan untuk adalah berikut. eran semantis konstituen pascafrasa direktif yang berunsur di adalah keadaan, pengalam, hasil, dan pelaku. Peran semantis konstituen pascafrasa direktif yang berunsur dari adalah pelaku, pertentangan, penderita, dan penyebab. Peran semantis konstituen pasca frasa direktif yang berunsur untuk adalah pengalam, pelaku,sasaran, dan tempat.

\section{DAFTAR PUSTAKA}

Alwi, dkk. 2003. Tata Bahasa Baku Bahasa Indonesia. Jakarata : Balai Pustaka.

Chaer, Abdul. 1990. Penggunaan Preposisi dan Konjungsi Bahasa Indonesia. Ende Flores: Nusa Indah.

Djajasudarma, T. Fatimah. 2003. Analisis Bahasa Sintaksis dan Semantik. Bandung: Uvula Press Fakultas SastraUniversitas Padjadjaran.

Kridalaksana, Harimurti. 1994. Kelas Kata dalam Bahasa Indonesia. Jakarta: PT Gramedia Pusata Utama.

Ramlan, M. 1987. Kata Depan atau Preposisi dalam Bahasa Indonesia. Yogyakarta: CV Karyono.

Sudaryanto. 1993. Metode dan Aneka Teknik Analisis Bahasa: Pengantar Penelitian Wahana Kebudayaan secara Linguistis. Yogyakarta: Duta Wacana University Press.

Verhaar, J.W.M. 2004. Asas-Asas Linguistik Umum. Yogyakarta: Gajah Mada University Press. Teknik Analisis Bahasa: Pengantar Penelitian Wahana Kebudayaan secara Linguistis. Yogyakarta: Duta Wacana University Press. 
